\title{
Inhibition of tyrosine phosphatases induces apoptosis independent from the CD95 system
}

\author{
Steffen P. Hehner ${ }^{1}$, Thomas G. Hofmann ${ }^{1}$, Wulf Dröge ${ }^{1}$ and \\ M. Lienhard Schmitz*,1 \\ 1 Department of Immunochemistry, German Cancer Research Center (DKFZ), Im \\ Neuenheimer Feld 280, Germany \\ * corresponding author: M Lienhard Schmitz, Department of Immunochemistry, \\ German Cancer Research Center (DKFZ), Im Neuenheimer Feld 280, 69120 \\ Heidelberg, Germany. tel: ++49-6221-423725; fax: ++49-6221-423746; \\ e-mail: L.Schmitz@DKFZ-Heidelberg.de
}

Received 27.1.99; revised 4.5.99; accepted 28.6.99

Edited by R. Knight

\begin{abstract}
The inhibition of protein tyrosine phosphatases by pervanadate, a potent activator of $B$ - and T-cells through the induction of tyrosine phosphorylation and downstream signaling events in different activation cascades, efficiently induced apoptosis in lymphoid cell lines. Pervanadate-elicited apoptosis could be blocked by the tyrosine kinase inhibitor herbimycin $A$. This apoptotic process involved the activation of caspases 3,8 and 9 , the induction of mitochondrial permeability transition, the release of cytochrome $\mathrm{C}$ and the fragmentation of chromosomal DNA. T-cells lacking the CD95 receptor or caspase-8 and T-cells stably overexpressing a transdominant negative form of the adaptor protein FADD were still susceptible to pervanadate-induced apoptosis, excluding the involvement of the CD95 system or other FADD-dependent death receptors. The apoptotic program initiated by the inhibition of tyrosine phosphatases did not require the presence of the tyrosine kinase $p 56^{\text {lck }}$ or phosphatase CD45, whereas Bcl-2 overexpression protected T-cells from pervanadate-induced cytochrome $C$ release, caspase- 8 cleavage and apoptosis.
\end{abstract}

Keywords: apoptosis; CD95 receptor; tyrosine phosphorylation

Abbreviations: CAD, caspase-activated deoxyribonuclease; DISC, death-inducing signaling complex; DN, dominant negative; FAP-1, Fas-associated phosphatase-1; NAC, N-acetyl-cysteine; PARP, poly (ADP ribose) polymerase; PTK, protein tyrosine kinase; wt, wild-type

\section{Introduction}

Apoptosis can be triggered by various stimuli such as $\mathrm{H}_{2} \mathrm{O}_{2}$ and UV-radiation or the activation of transcription factors cMyc, p53 and the glucocorticoid receptor. Alternatively, apoptosis is induced upon ligation of structurally related cell surface receptors belonging to the family of death receptors including CD95 (APO-1/Fas) and tumor necrosis factor (TNF) receptors. ${ }^{1}$ Many apoptotic programs such as the activation-induced cell death in T-cells are executed by upregulation of the CD95 ligand, thereby activating the CD95 receptor-mediated apoptosis program. ${ }^{2}$ Binding of the extracellular ligands leads to trimerization of the respective receptors and aggregation of their intracellular domains. CD95 ligation leads to the formation of a deathinducing signaling complex (DISC), which contains multiple proteins including the intracellular ligand FADD. ${ }^{3}$ The FADD protein also interacts with the cytoplasmic domains of other death receptors and binds the protease caspase8. ${ }^{4}$ CD95-mediated apoptosis is executed by at least two different signaling pathways. The amount of caspase-8 activated at the DISC seems to determine whether a mitochondria-dependent or -independent signaling route is taken. ${ }^{5}$ Most likely, the mitochondrial pathway is mediated by cleavage and thus activation of caspase- 8 which results in the fragmentation of the proapoptotic Bid protein. ${ }^{6}$ The Bid cleavage product then contributes to the mitochondrial changes, which result in the formation of mitochondrial permeability transition pores, the reduction of the mitochondrial transmembrane potential $\Delta \Psi_{\mathrm{m}}$ and the release of cytochrome $C$. The latter interacts with an Apaf-1/caspase9-containing complex, an event that results in the caspase9 activation. $^{7}$ Activated caspase- 9 then cleaves and activates caspase-3, thus initiating a branched protease cascade where each of the activated caspases controls distinct downstream processes. The analysis of mice either lacking caspase- 9 or Apaf- 1 shows, that the cell type and the nature of the apoptotic stimulus determines the

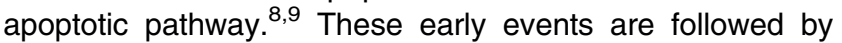
the cleavage of cellular substrate proteins including poly (ADP ribose) polymerase (PARP) and ICAD, an inhibitory protein for the caspase-activated deoxyribonuclease (CAD). This nuclease cuts the genomic DNA in the internucleosomal regions, thus generating multimers of domain-sized fragments. ${ }^{10}$

The role of serine/threonine phosphorylation in apoptosis is much better understood than the role of tyrosine phosphorylation, which does not yield a homogeneous picture yet. Apoptosis-promoting properties of tyrosine phosphorylation are seen in experiments, where diverse inhibitors of protein tyrosine kinases (PTKs) such as genistein, tyrphostin and herbimycin $\mathrm{A}$ provide a protection against hypoxia-induced apoptosis. ${ }^{11}$ Also overexpression of the proline-rich tyrosine kinase 2 induces cell death in fibroblasts. ${ }^{12}$ Activation of the SAPK/JNK pathway by TGF$\beta$ results in the induction of transcription factor DPC4, which leads to cell cycle arrest and the onset of apoptosis. $^{13}$ Similarly, triggering the STAT pathway in HeLa cells by IFN- $\gamma$ results in the induced expression of caspase- 1 and the onset of cell death. ${ }^{14}$ However, there is also evidence for antiapoptotic effects of tyrosine phosphorylation. The inhibition of epidermal growth factor receptor tyrosine kinase results in apoptosis. ${ }^{15} \mathrm{~A}$ B-cell 
line lacking the tyrosine kinase Syk dies more efficiently by apoptosis induced by hyperosmotic stress than the wildtype cell line. ${ }^{16}$

Binding of the $\mathrm{T}$ - and $\mathrm{B}$-cell receptors results in the activation of numerous PTKs, which trigger different signaling cascades including the mitogen-activated protein kinase pathways and the activation of transcription factors. ${ }^{17-19}$ Tyrosine phosphorylation can be induced by pervanadate (vanadate peroxide), which irreversibly inhibits protein tyrosine phosphatases such as CD45 by oxidizing catalytic cysteines. ${ }^{20}$ Therefore, pervanadate is a widely used inducer of tyrosine phosphorylation, a process that is normally mediated by PTKs. The pervanadate-elicited phosphorylation of cellular regulators makes pervanadate a widely used tool to mimic stimulation of B-cell signaling cascades, activation of the T-cell receptor complex and physiologic processes such as reoxygenation. ${ }^{17,21-23}$

Here we identify pervanadate-induced tyrosine phosphorylation as a potent inducer of apoptosis in lymphoid cells. Inhibition of tyrosine phosphatases resulted in a rapid reduction of $\Delta \Psi_{\mathrm{m}}$, the release of cytochrome $\mathrm{C}$, activation of caspases 9,8 and 3 as well as the fragmentation of chromosomal DNA. T-cells lacking CD95 or overexpressing a dominant negative form of FADD were still susceptible to cell death induced by the inhibition of tyrosine phosphatases. This apoptotic process could be inhibited by $\mathrm{Bcl}-2$ overexpression and did not require tyrosine kinase $\mathrm{p} 56^{\mathrm{lck}}$ or phosphatase CD45. These results identify early premitochondrial signaling events as the target for the novel apoptotic stimulus described here.

\section{Results}

\section{Pervanadate: a novel and effective inducer of apoptosis in $\mathrm{T}$ lymphocytes}

During a set of experiments using pervanadate as a stimulus for T-cell activation, we noticed that prolonged periods of pervanadate-treatment induced morphological changes reminiscent to apoptotic processes. We followed this initial finding by exposing human Jurkat T-cells for various time periods to different concentrations of pervanadate. Analysis of the cellular DNA by flow cytometry revealed the characteristic 'sub G1' peak that is indicative for apoptosis (data not shown). Pervanadate in a concentration of $100 \mu \mathrm{M}$ already killed the cells in a kinetics that was only slightly slower than apoptosis induced by $\alpha$-APO-1 antibodies. A pervanadate concentration of $50 \mu \mathrm{M}$ was only effective when kept on the cells for 2 days (Figure 1A). The apoptotic process was further characterized by the analysis of DNA laddering, another typical feature of apoptosis. Jurkat cells were treated with various concentrations of pervanadate for 12 and $24 \mathrm{~h}$, and the genomic DNA was analyzed by electrophoresis on agarose gels. Pervanadate in a concentration of $100 \mu \mathrm{M}$ was already sufficient to induce the typical cleavage of chromosomal DNA into multimers of nucleosomal domain-sized fragments (Figure 1B). The addition of the PTK inhibitor herbimycin A completely suppressed pervanadate-induced apoptosis (Figure 2A), demonstrating the importance of tyrosine phosphorylation for this apoptotic pathway. Similarly, millimolar concentrations of the antioxidative compound $\mathrm{N}$-acetyl-cysteine (NAC) protected Jurkat cells from pervanadate-induced apoptosis (Figure 2B), highlighting the role of reactive oxygen species for this apoptotic process.

\section{Inhibition of tyrosine phosphatases results in the activation of caspase-3 and $\mathbf{- 8}$}

To determine the role of caspases in the course of pervanadate-elicited apoptosis we tested the impact of synthetic peptide inhibitors displaying different specificities for various caspases. The broad spectrum irreversible inhibitor zVAD-fmk prevented pervanadate-induced apoptosis almost completely (Figure $3 \mathrm{~A}$ ). The same concentration of the inhibitor Ac-YVAD-CHO was less efficient in the protection of Jurkat cells, suggesting that group I caspases (caspase-1, -4 and -5 ) are of minor importance for pervanadate-induced apoptosis. However, the participation of these group I caspases cannot completely be ruled out, since different cell permeability characteristics of aldehyde and fluoromethylketone conjugates have to be considered. Pervanadateinduced apoptosis was prevented in the presence of DEVD-

A

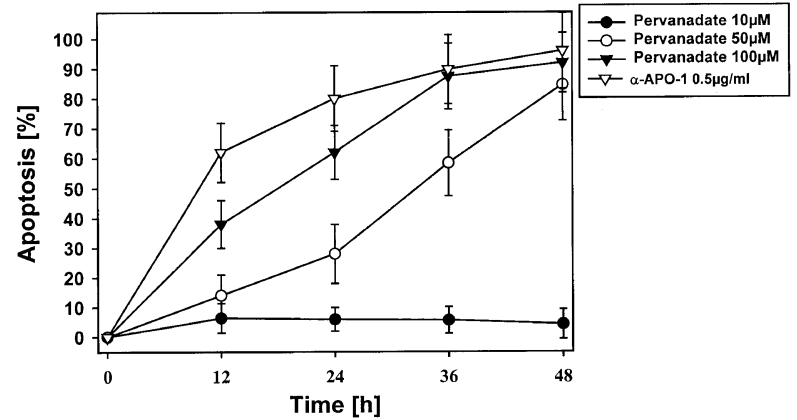

B

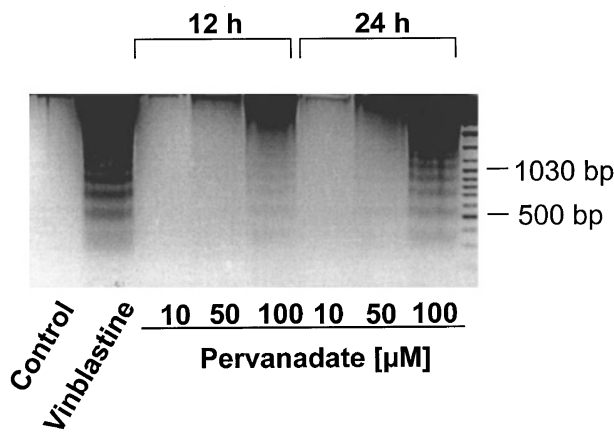

Figure 1 Induction of apoptosis by inhibition of tyrosine phosphatases. (A) The indicated concentrations of pervanadate and $\alpha$-APO- 1 antibodies were added to Jurkat cells. Apoptosis was measured at the time points given by FACS analysis and the percentage of hypoploid cells is shown. Bars indicate the standard deviations from three independent experiments. (B) Jurkat cells were cultured in the presence of pervanadate as indicated. Vinblastine was used as a positive control $(1 \mu \mathrm{M}$ for $12 \mathrm{~h})$. The fragmentation of DNA into oligonucleosomes was determined by horizontal agarose gel electrophoresis followed by staining with ethidium bromide. A representative experiment is shown 
cmk, a peptide that efficiently prevents the activation of caspases-3, -7 and $-8,{ }^{24}$ suggesting an important role for at least one of these enzymes. The involvement of caspase-8, caspase- 3 and the caspase substrate protein PARP was further investigated by following the fate of these proteins for various time periods in the presence of $100 \mu \mathrm{M}$ pervanadate. The cleavage products were already detectable after $180 \mathrm{~min}$ by Western blot experiments (Figure 3B). This experiment shows the direct activation of caspases 8 and 3 during this apoptotic process.

\section{Pervanadate-induced cell death is prevented by $\mathrm{Bcl}-2$ overexpression and does not require the CD95 receptor system}

Each of the two CD95 signaling pathways described in a recent study ${ }^{5}$ is almost exclusively used in two types of cells. Type I cells are killed by a mitochondria-independent pathway and type II cells utilize a mitochondria-dependent signaling cascade. In order to test whether pervanadate preferentially affects the signaling routes employed by type I or type II cells,

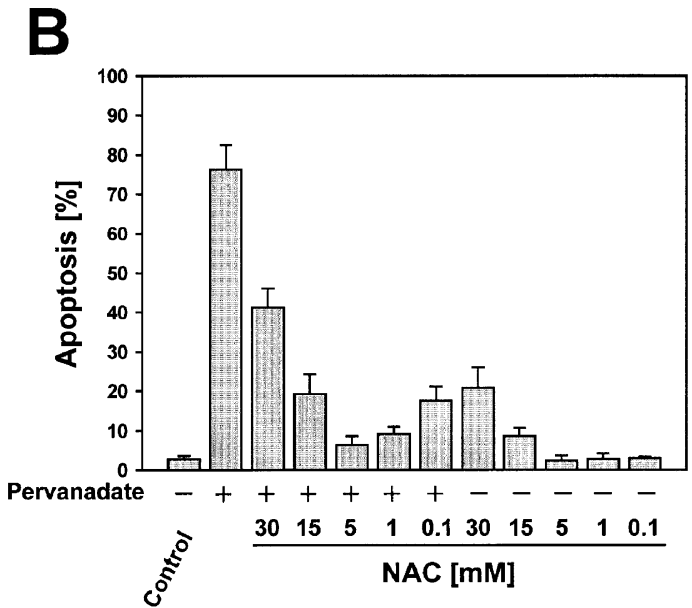

Figure 2 Inhibitors of pervanadate-induced apoptosis. (A) Prior to the addition of $100 \mu \mathrm{M}$ of pervanadate for $24 \mathrm{~h}$, Jurkat cells were exposed for $18 \mathrm{~h}$ to the indicated concentrations of herbimycin A. (B) The experiment was performed as described for (A), with the exception that the indicated concentrations of NAC were added $1 \mathrm{~h}$ prior to the induction of apoptosis by pervanadate. Error bars indicate the standard deviations

A

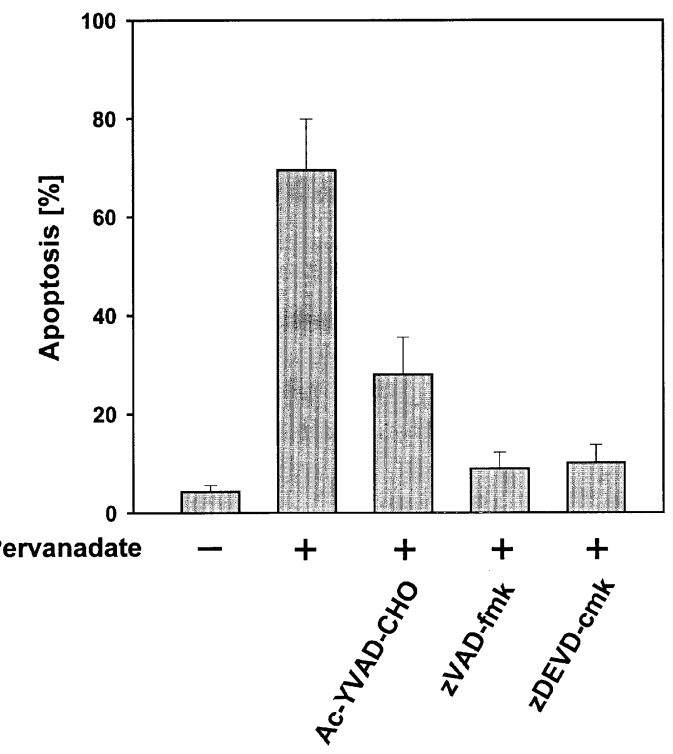

B

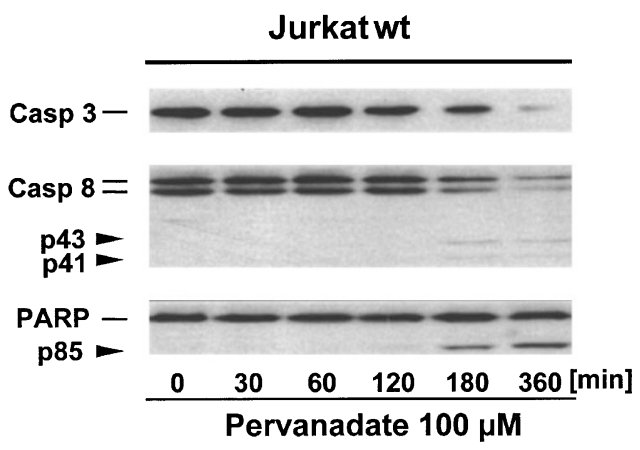

Figure 3 Activation of caspases. (A) The caspase inhibitors zVAD-fmk, Ac-YVAD-CHO and zDEVD-cmk were added $1 \mathrm{~h}$ prior to addition of $100 \mu \mathrm{M}$ pervanadate for $24 \mathrm{~h}$ at concentrations of $75 \mu \mathrm{M}$, respectively. The percentage of apoptotic cells was measured by FACS analysis, bars represent the standard deviation from three independent experiments. (B) Jurkat T-cells were treated for various periods with $100 \mu \mathrm{M}$ pervanadate. Equal amounts of cellular proteins contained in total cell extracts were subjected to SDS-PAGE and analyzed by Western blotting for caspase-3, -8 and PARP. Lines show the full length forms of the proteins, arrowheads indicate the cleavage products 
we compared various type I and type II cell lines for their susceptibility to apoptosis induced by pervanadate or $\alpha$-APO1 (Figure 4A). The five cell lines tested were efficiently killed by $\alpha$-APO- 1 antibodies. All type II cells (Jurkat and CEM-C7 Tcells and BJAB B-cells) died upon exposure to pervanadate, but both type I cells tested (SKW 6.4 B-cells and H9 T-cells) were not significantly killed by pervanadate. This raises the possibility that only type II cells are targets for this apoptotic stimulus. Since pervanadate leads to caspase-8 cleavage and the activation of T-cells, we tested whether it may exert its apoptotic function by upregulation of the CD95 ligand. A T-cell line lacking the CD95 receptor (CD95 ${ }^{-}$cells) ${ }^{25}$ was exposed either to $\alpha$-APO-1 antibodies or to pervanadate and the apoptosis rate was measured by FACS analysis (Figure 4B). The CD95 ${ }^{-}$cells were completely resistant to CD95-induced cell death, but readily died upon exposure to pervanadate. In order to test the possible involvement of the death receptorassociated FADD protein which serves as an adaptor protein for several death receptors, we generated Jurkat cell lines stably overexpressing a dominant negative (DN) form of FADD ${ }^{26}$ lacking the death effector domain (data not shown). Jurkat cells overexpressing FADD DN were not killed by
A

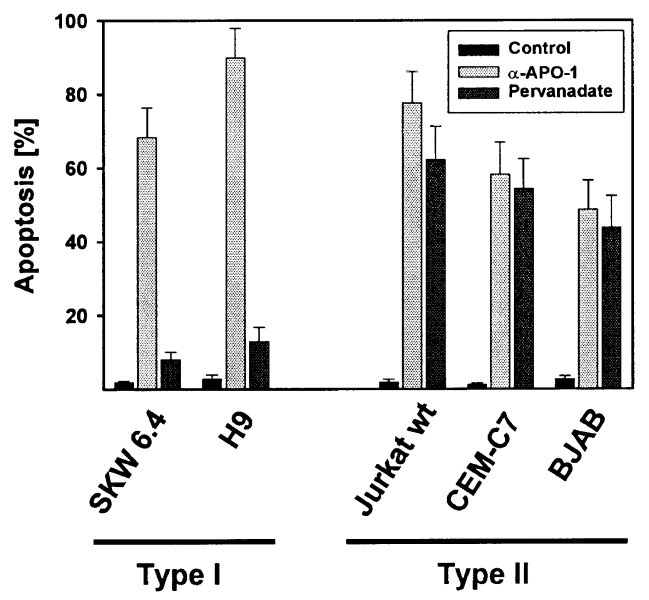

B

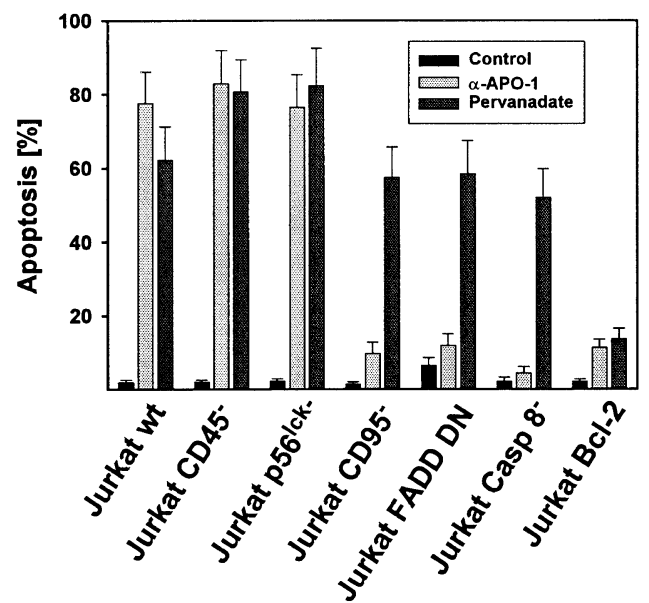

C

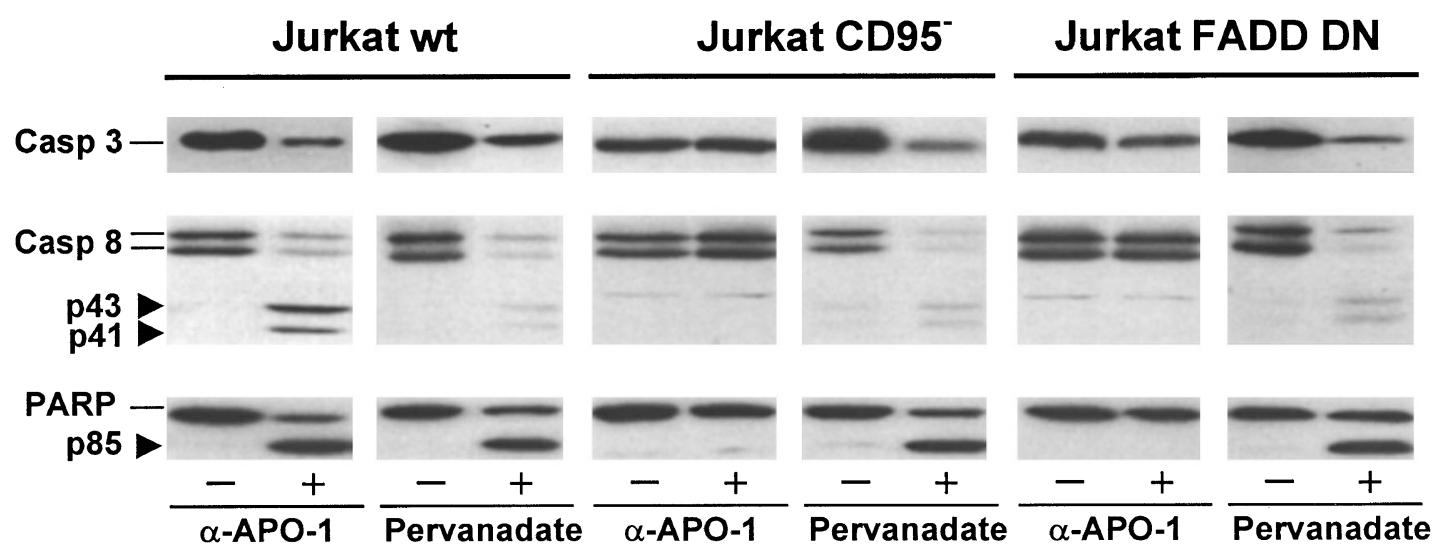

Figure 4 Comparative analysis of CD95- and pervanadate-triggered apoptosis in various cell-types. (A) The indicated type I and type II cells were treated either for $24 \mathrm{~h}$ with $100 \mu \mathrm{M}$ pervanadate or for $12 \mathrm{~h}$ with $\alpha$-APO-1 $(1 \mu \mathrm{g} / \mathrm{ml})$. Apoptosis was determined by measuring the percentage of hypoploid cells, the standard deviations from three experiments are displayed by bars. (B) The indicated cell lines and derivatives thereof were treated and analyzed as in (A). (C) The indicated cell types were treated either with $\alpha$-APO-1 antibodies $(3 \mathrm{~h})$ or $100 \mu \mathrm{M}$ pervanadate $(6 \mathrm{~h})$ and analyzed by Western blotting for the cleavage of caspase-3, -8 and PARP as shown in Figure 3B 
agonistic $\alpha$-APO- 1 antibodies, but died in the presence of pervanadate. These results show that neither the CD95 receptor nor the FADD molecule, which is associated to several different death receptors, are required for this apoptotic process. We then tested the importance of caspase-8, another component of the DISC. Caspase-8 deficient Jurkat cells ${ }^{27}$ were protected from CD95-mediated cell killing, but retained their sensitivity to the apoptotic signals provided by pervanadate (Figure 4B). In addition, Jurkat cells lacking the PTK p56 ${ }^{\text {lck }}$ and the phosphatase CD45, ${ }^{20}$ two known pervanadate targets, were included in these experiments. Both cell lines were killed by the inhibition of tyrosine phosphatases and $\alpha$-APO-1 antibodies, showing that both molecules are not essential for these apoptotic processes. The antiapoptotic Bcl-2 protein prevents cell death by many, but not all, apoptotic stimuli. However, this antiapoptotic function affects processes during the initiation phase of apoptosis and is not seen when active caspases are directly microinjected into the cells. ${ }^{28}$ Therefore the impact of CD95 ligation and pervanadate treatment on T-cells overexpressing Bcl-2 was tested. The overexpressing cells were protected from $\alpha$-APO-1- and pervanadate-induced apoptosis (Figure 4B).

Next, we compared the cleavage of caspase-3, -8 and PARP between Jurkat wild-type (wt) cells and its CD95 ${ }^{-}$ and FADD DN derivatives. In Jurkat wt cells, the addition of $\alpha$-APO-1 antibodies and pervanadate induced the cleavage of caspase-3, caspase-8 and PARP (Figure 4C). In CD95 ${ }^{-}$ cells these three proteins were efficiently activated in the presence of pervanadate, but not upon addition of $\alpha$-APO-1 antibodies. Pervanadate treatment resulted in the cleavage of caspase-3, -8 and PARP in the Jurkat cells constitutively overexpressing FADD DN, but these three proteins remained almost completely intact upon CD95 ligation. In summary, these experiments indicate that pervanadate targets events downstream from the CD95 receptor system.

\section{Apoptosis induced by inhibition of tyrosine phosphatases involves the release of cytochrome $\mathrm{C}$ and a decrease of the mitochondrial transmembrane potential}

The generation of mitochondrial permeability transition pores and a drop in the transmembrane potential $\Delta \Psi_{\mathrm{m}}$ are considered to be the 'point of no return' during various apoptotic signaling pathways. ${ }^{29}$ Since some apoptotic pathways are known to bypass mitochondrial events, ${ }^{5}$ we tested the effects of pervanadate treatment on mitochondrial changes. Jurkat T-cells were treated with pervanadate for various periods and the mitochondrial transmembrane potential $\Delta \Psi_{\mathrm{m}}$ was measured by using DiOC6(3) (Figure $5 \mathrm{~A})$. Within $2 \mathrm{~h}$ approximately $50 \%$ of the cells showed a decreased $\Delta \Psi_{\mathrm{m}}$ when compared to the untreated cells. The percentage of pervanadate-treated cells with a low $\Delta \Psi_{\mathrm{m}}$ was even higher than in the positive control (CD95 ligation).

The mitochondrial events during this apoptotic process were further characterized by analyzing the release of cytochrome $\mathrm{C}$ from the mitochondria. Jurkat cells stably transfected either with an empty expression vector (Jurkat neo) or with an expression vector encoding $\mathrm{Bcl}-2$, were treated for $6 \mathrm{~h}$ with $100 \mu \mathrm{M}$ of pervanadate or $\alpha$-APO-1 antibodies. After fractionation of cells into a mitochondrial and a cytosolic S100 fraction, cytochrome C was detected by Western blotting. Cytochrome $\mathrm{C}$ was efficiently released into the cytosol of the $\alpha$-APO-1- and pervanadate-treated Jurkat wt cells (Figure 5B). In contrast, the Jurkat Bcl-2 cells showed no cytochrome $\mathrm{C}$ release, indicating that $\mathrm{Bcl}-2$ exerts its protective effects during this apoptotic pathway prior to the onset of mitochondrial events. The released cytochrome $\mathrm{C}$ enables the dATP-dependent activation of the caspase-9/Apaf-1 complex. ${ }^{6}$ The activation of caspase9 in response to pervanadate was determined by measuring the induced light emission of a caspase-9specific fluorogenic peptide substrate. Already $3 \mathrm{~h}$ after the addition of the tyrosine phosphatase inhibitor, caspase- 9 was activated to an extent comparable to ligation of the CD95 receptor (Figure $5 \mathrm{C}$ ). A possible mechanism which might explain the effects elicited by pervanadate is a caspase-8 activation which in turn would cause the observed mitochondrial changes. Since overexpression of Bcl-2 blocks caspase- 8 cleavage in type II cells, ${ }^{5}$ we asked whether this caspase would also be affected by pervanadate treatment in Bcl-2 overexpressing Jurkat cells. These cells were treated with pervanadate and the fate of caspase-3, -8 and PARP was followed by immunoblotting (Figure 5D). Pervanadate did not induce cleavage of both caspases and PARP in the Bcl-2 overexpressing Jurkat cells. A similar experimental approach was applied to investigate whether caspase-8 is necessary for the commitment to pervanadate-induced apoptosis. Exposure of caspase- $8^{-}$cells to pervanadate resulted in the activation of caspase- 3 and the cleavage of PARP (Figure 5D), showing that pervanadate can induce caspase activation in the absence of caspase-8. Taken together, these results show that pervanadate targets early apoptotic signaling steps prior to the activation of the mitochondrial pathways.

\section{Discussion}

Here we have identified pervanadate as a potent inducer of apoptosis. The inhibition of tyrosine phosphatases efficiently initiated an apoptotic program within $24 \mathrm{~h}$. The apoptotic potential of pervanadate relied on its ability to induce tyrosine phosphorylation, as shown by the inhibitory effect of herbimycin A. The molecular target(s) for this apoptosisinducing tyrosine phosphorylation are not known so far. Apparently, neither the PTK p56 ${ }^{\text {lck }}$ nor CD45, an enzyme that regulates many kinases including $\mathrm{p} 59^{\mathrm{fyn}}$ and $\mathrm{p} 56^{\mathrm{lck}}, 30$ are involved in pervanadate-induced apoptosis. Also the CD95 receptor and the DISC components FADD and caspase- 8 are not required for the execution of pervanadate-elicited cell death. The apoptotic program initiated by pervanadate follows a common Bcl-2 inhibitable pathway upstream from the mitochondrial events including the reduction of the mitochondrial transmembrane potential and release of cytochrome C. The execution of this apoptotic pathway is accompanied by the cleavage and activation of caspases 3, 8 and 9 and the fragmentation of chromosomal DNA. Not all cell lines were 
A

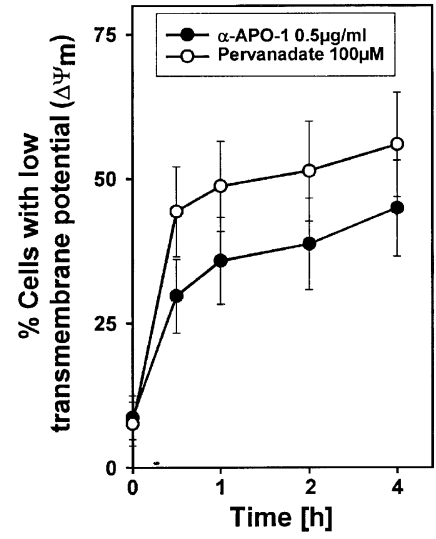

C

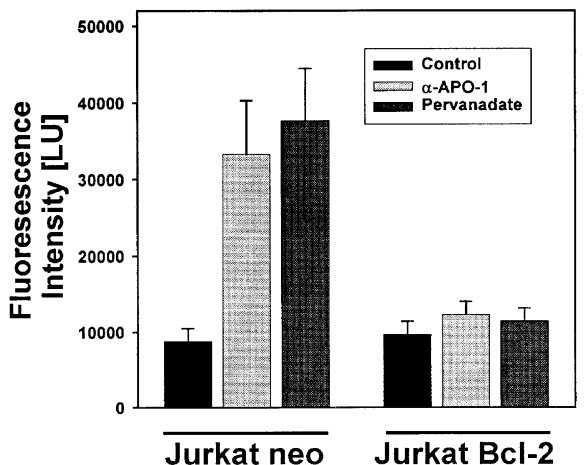

B Jurkat neo Jurkat Bcl-2

S 100

Mitos

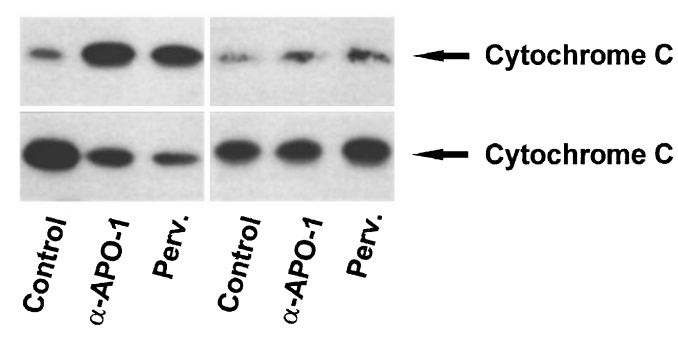

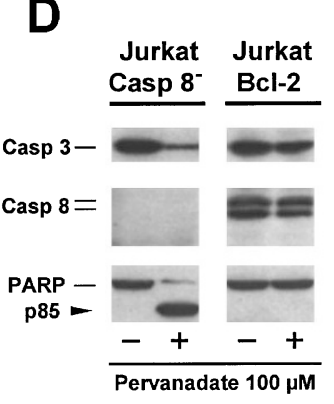

Figure 5 Mitochondrial events during pervanadate-initiated apoptosis. (A) Jurkat T-cells were treated with $\alpha$-APO- 1 antibodies $(0.5 \mu \mathrm{g} / \mathrm{ml})$ or $100 \mu \mathrm{M}$ pervanadate for various time periods as indicated. Subsequently cells were stained and the green fluorescence emitted by the DiOC6(3) dye was determined by FACS analysis. Mean values of three independent experiments performed in duplicate are shown, bars indicate the standard deviations. (B) Jurkat neo cells and Jurkat Bcl-2 overexpressing cells were treated either for $6 \mathrm{~h}$ with $\alpha$-APO-1 antibodies $(1 \mu \mathrm{g} / \mathrm{ml})$ or for $6 \mathrm{~h}$ with $100 \mu \mathrm{M}$ pervanadate. Proteins contained in cytosolic S100 extracts and the mitochondrial fraction were analyzed by Western blotting for the occurrence of cytochrome C. (C) Cells were treated as in (B) and cell extracts were incubated with the fluorogeneic peptide LEHD-AFC. The AFC product of the reaction was measured after $2 \mathrm{~h}$ of incubation using a plate reader. Mean values of the light units (LU) measured in two independent experiments performed in duplicate are shown, bars indicate the standard deviations. (D) Jurkat Bcl-2 overexpressing and caspase $-8^{-}$cells were treated for $6 \mathrm{~h}$ with $100 \mu \mathrm{M}$ pervanadate and analyzed for the cleavage of caspase-3, -8 and PARP by immunoblotting. A typical experiment is shown

susceptible to the apoptotic signals provided by the inhibition of tyrosine phosphatases. Interestingly, all type I cells tested were resistant and all tested type II cells were susceptible to pervanadate. Assuming that this arrangement is not coincidental, this finding raises the possibility that phosphatases display distinct roles in transducing apoptotic signals in type and type II cells. In addition, the role of tyrosine phosphorylation can also depend on the nature of the apoptotic stimulus. The inhibition of epidermal growth factor receptor tyrosine kinase results in apoptosis, ${ }^{15}$ but the nerve growth factor can prevent programmed cell death through stimulation of the TrkA receptor protein tyrosine kinase. ${ }^{31}$

CD95 ligation results in an increased tyrosine phosphorylation of cellular proteins, thus providing a rationale for the previous finding that pharmacological tyrosine kinase inhibitors prevent CD95-induced DNA fragmentation. ${ }^{32}$ The activated kinases include $\operatorname{Lyn}^{33}$ and MEKK1, which is proteolytically activated by caspase cleavage. ${ }^{34-36}$ In this context it is noteworthy, that two phosphatases have been reported to interact with the CD95 receptor: the Fasassociated phosphatase-1 (FAP-1) and the tyrosine phosphatase PTPL1. ${ }^{37,38}$ However, the functional impact of these associated phosphatases on CD95-mediated cell killing is not established yet ${ }^{39}$ and it remains to be seen whether further and so far unidentified DISC proteins are kinases or phosphatases. In support to the data presented here, the induction of tyrosine phosphorylation induces a regional, selective neuronal degeneration in hippocampal slice cultures. ${ }^{40}$ Also the TNF-mediated cell death can be modulated by tyrosine phosphorylation events. Here, inhibition of the expression of mitogen-activated phosphatase 1 potentiates TNF- $\alpha$-induced apoptosis in mesangial cells. ${ }^{41}$ One possible mechanism for the death promoting activity of tyrosine phosphorylation may be provided by the previous finding that the induced phosphorylation of tyrosine 331 , which is located in the cytoplasmatic domain of TNF-receptor 1 , leads to the dissociation of the receptorassociated kinase p60TRAK. ${ }^{42}$ 
This study does not address the question whether an increase or decrease of tyrosine phosphorylation acts as a general pro- or antiapoptotic signal. It seems that there may be a subtle balance of tyrosine phosphorylation that modulates the early signaling events of the apoptotic response. This might explain why the lowest concentration of herbimycin $A$ is the most effective in preventing pervanadate-induced apoptosis. By contrast, the highest concentration of herbimycin A was also slightly cytotoxic (Figure 2A). Well-defined events at the cell surface such as activation of the insulin receptor or T-cell receptor lead to the onset of distinct tyrosine phosphorylation cascades. Adverse conditions such as UV radiation or reoxygenation after hypoxia are known to cause a massive induction of numerous parallel tyrosine kinase pathways. ${ }^{23}$ We speculate that the simultaneous activation of many PTK signaling cascades inundating the cell leads to a loss of control and the onset of the apoptotic program. This study demonstrates that these phosphorylation events target the early steps during the initiation phase of apoptosis independent from the CD95 system.

\section{Materials and Methods}

\section{Apoptosis inhibitors}

The caspase inhibitors N-benzyloxycarbonyl-Val-Ala-Asp-fmk (zVADfmk), acetyl-Tyr-Val-Ala-Asp-aldehyde (Ac-YVAD-CHO) and $\mathrm{N}$ benzyloxycarbonyl-Asp-Glu-Val-Asp-cmk (zDEVD-cmk) were purchased from Enzyme System Products (Eugene, OR, USA). Herbimycin A and NAC were from Sigma (St. Louis, MO, USA).

\section{DNA fragmentation assay}

Apoptosis was induced either by vinblastine or by pervanadate, which was generated by incubation of equimolar concentrations of $\mathrm{H}_{2} \mathrm{O}_{2}$ and sodium vanadate for $20 \mathrm{~min}$ at room temperature. Cells were collected by centrifugation and washed twice with phosphate-buffered saline. They were lyzed in $0.5 \times$ TBE $(25 \mathrm{mM}$ TRIS, $25 \mathrm{mM}$ boric acid and $0.5 \mathrm{mM}$ EDTA) containing $0.25 \%(\mathrm{v} / \mathrm{v}) \mathrm{NP}-40$ and $0.5 \mathrm{mg} / \mathrm{ml}$ RNAseA. After incubating the samples for $45 \mathrm{~min}$ at $37^{\circ} \mathrm{C}, 0.5 \mathrm{mg} / \mathrm{ml}$ Proteinase K (Sigma Inc., St. Louis, MO, USA) was added for another $45 \mathrm{~min}$ at $37^{\circ} \mathrm{C}$. The cell debris was pelleted upon centrifugation with 14000 r.p.m. at $4^{\circ} \mathrm{C}$ for $10 \mathrm{~min}$. The DNA-fragments contained in the supernatant were transferred into a new Eppendorf tube and separated on a $1.5 \%(\mathrm{w} / \mathrm{v})$ agarose gel in $1 \times$ TBE buffer at $50 \mathrm{~V}$ for $3 \mathrm{~h}$. The ethidium bromide-stained DNA was analyzed and photographed under ultraviolet light.

\section{Cell culture}

CEM-C7, H9, BJAB, SKW 6.4, Jurkat T leukemia cells and their p56 $6^{\text {lck. }}$ (Jurkat JCam1.6), CD45- (Jurkat CD45 45.01), CD95 ${ }^{-}$and caspase $8^{-}$derivatives as well as the Jurkat cells overexpressing Bcl-2, and FADD DN were grown at $37^{\circ} \mathrm{C}$ in RPMI 1640 medium containing $10 \%$ heat-inactivated fetal calf serum, $10 \mathrm{mM}$ HEPES and $1 \%(\mathrm{v} / \mathrm{v})$ penicillin/streptomycin (all from Life Technologies, Grand Island, NY, USA). The Bcl-2 and FADD DN expressing cells were selected by the addition of G418 $(2 \mathrm{mg} / \mathrm{ml})$ to the medium. All cells were kept in an humidified incubator at $37^{\circ} \mathrm{C}$ and $5 \% \mathrm{CO}_{2}$.

\section{Detection of apoptosis by FACS analysis}

Apoptosis was determined by measuring DNA fragmentation after lyzing the cells in a hypotonic buffer containing $50 \mu \mathrm{g} / \mathrm{ml}$ propidium iodide, $0.1 \%(\mathrm{w} / \mathrm{v})$ sodium citrate and $0.1 \%(\mathrm{v} / \mathrm{v})$ Triton X-100 (all from Sigma Inc., St. Louis, MO, USA). DNA fluorescence was determined in a FACScan as described. ${ }^{43}$ The results were analyzed with CELLQuest software (Becton Dickinson, Heidelberg, Germany).

\section{Determination of the mitochondrial transmembrane potential and cytochrome C release}

Cells were incubated with $100 \mathrm{nM} 3,3^{\prime}$-dihexyloxacarbocyanine iodide DiOC6(3) (Molecular Probes, Leiden, The Netherlands) in phosphatebuffered saline for $15 \mathrm{~min}$ at $37^{\circ} \mathrm{C}$. Dead cells were excluded by staining with propidium iodide and forward/sideward scatter gating using a FACScan flow cytometer (Becton Dickinson, Heidelberg, Germany). The cytochrome $C$ release was measured essentially as described. ${ }^{44}$

\section{Determination of caspase-9 activation}

A total of $10^{6}$ Jurkat cells was washed with phosphate-buffered saline and lysed in buffer A (100 mM HEPES, 10\% (w/v) sucrose, $10 \mu \mathrm{M}$ leupeptin, $10 \mu \mathrm{M}$ aprotinin, $1 \mathrm{mM}$ EDTA, $5 \mathrm{mM}$ DTT, and $0.15 \%(\mathrm{v} / \mathrm{v})$ 3-cholamidopropyl-dimethylammonio-1-propansulfate, $\mathrm{pH} 7.4$ ). To determine caspase- 9 activity, $10 \mu \mathrm{l}$ of cell lysates were incubated with $20 \mu \mathrm{l}$ (final concentration $75 \mu \mathrm{M}$ ) of fluorogeneic peptide LEHDAFC. After several hours of incubation, the reaction product was measured (excitation $405 \mathrm{~nm}$, emission $535 \mathrm{~nm}$ ) using a plate reader (Victor 1420, Wallac, Freiburg, Germany).

\section{Western blotting}

Cell extracts contained in TOTEX buffer were separated by SDSPAGE and blotted onto a polyvinylidene difluoride membrane (Millipore, Bedford, MA, USA), using a semi-dry blotting apparatus (Bio-Rad, Munich, Germany). The membrane was blocked with $5 \%$ non-fat dry milk powder in TBST buffer $(25 \mathrm{mM}$ Tris/ $\mathrm{HCl}, \mathrm{pH} 7.4$, $137 \mathrm{mM} \mathrm{NaCl}, 5 \mathrm{mM} \mathrm{KCl}, 0.7 \mathrm{mM} \mathrm{CaCl}_{2}, 0.1 \mathrm{mM} \mathrm{MgCl}_{2}, 0.05 \%$ (v/v) Tween 20). The membrane was then incubated in a small volume of TBST containing a 1:2000 dilution of the antibodies (caspase-3: Transduction Laboratories, Lexington, KY, USA; caspase-8 (C15), ${ }^{45}$ cytochrome C: Pharmingen Inc. San Diego, CA, USA). The proteins were detected after extensive washing with a horseradish peroxidasecoupled secondary antibody using the ECL system according to the instructions of the manufacturer (Amersham Lifescience, Braunschweig, Germany).

\section{Acknowledgements}

We thank Dr. Burkhart Schraven (Heidelberg, Germany) for the Jurkat p56 ${ }^{\text {lck- }}$ and CD45 ${ }^{-}$cells, Dres. Peter Juo and John Blenis (Boston, MA, USA) for Jurkat caspase- $8^{-}$cells as well as Dr. Alexander Bürkle (Heidelberg, Germany) for $\alpha$-PARP antibodies. We are grateful to Dr Marcus E. Peter (Heidelberg, Germany) for antibodies recognizing CD95 $\left(\alpha\right.$-APO-1) and caspase- 8 and for providing Jurkat $\mathrm{CD}^{-} 5^{-}$and $\mathrm{Bcl}-2$ overexpressing Jurkat cells. This work was supported by the Cooperation Program in Cancer Research of the Deutsches Krebsforschungszentrum (DKFZ) and Israel's Ministry of Science (to W. Dröge and S.P. Hehner). 


\section{References}

1. Wallach D, Boldin M, Varfolomeev E, Beyaert R, Vandenabeele P and Fiers $W$ (1997) Cell death induction by receptors of the TNF family: towards a molecular understanding. FEBS Lett. 410: 96-106

2. Schulze-Osthoff K, Ferrari D, Los M, Wesselborg S and Peter ME (1998) Apoptosis signaling by death receptors. Eur. J. Biochem. 254: 439-459

3. Baker SJ and Reddy EP (1998) Modulation of life and death by the TNF receptor superfamily. Oncogene 17: $3261-3271$

4. Muzio M, Chinnaiyan AM, Kischkel FC, O'Rourke K, Shevchenko A, Ni J, Scaffidi C, Bretz JD, Zhang M, Gentz R, Mann M, Krammer PH, Peter ME and Dixit VM (1996) FLICE, a novel FADD-homologous ICE/CED-3-like protease, is recruited to the CD95 (Fas/APO-1) death-inducing signaling complex. Cell 85: 817-827

5. Scaffidi C, Fulda S, Srinivasan A, Friesen C, Li F, Tomaselli KJ, Debatin KM, Krammer PH and Peter ME (1998) Two CD95 (APO-1/Fas) signaling pathways. EMBO J. 17: 1675-1687

6. LiH, Zhu H, Xu CJ and Yuan J (1998) Cleavage of BID by Caspase 8 mediates the mitochondrial damage in the Fas pathway of apoptosis. Cell 94: 491-501

7. Li P, Nijhawan D, Budihardjo I, Srinivasula SM, Ahmad M, Alnemri ES and Wang X (1997) Cytochrome $C$ and dATP-dependent formation of Apaf- $1 /$ Caspase- 9 complex initiates an apoptotic protease cascade. Cell 91: 479-489

8. Hakem R, Hakem A, Duncan GS, Henderson JT, Woo M, Soengas MS, Elia A, de la Pompa JL, Kagi D, Khoo W, Potter J, Yoshida R, Kaufman SA, Lowe SW, Penninger JM and Mak TW (1998) Differential requirement for Caspase 9 in apoptotic pathways in vivo. Cell 94: 339-352

9. Yoshida H, Kong YY, Yoshida R, Elia AJ, Hakem A, Hakem R, Penninger JM and Mak TW (1998) Apaf1 is required for mitochondrial pathways of apoptosis and brain development. Cell 94: 739-750

10. Sakahira H, Enari M and Nagata S (1998) Cleavage of CAD inhibitor in CAD activation and DNA degradation during apoptosis. Nature 391: $96-99$

11. Hagar H, Ueda Nand Shah SV (1997) Tyrosine phosphorylation in DNA damage and cell death in hypoxic injury to LLC-PK1 cells. Kidney Int. 51: 1747-1753

12. Xiong W and Parsons JT (1997) Induction of apoptosis after expression of PYK2, a tyrosine kinase structurally related to focal adhesion kinase. J. Cell Biol. 139: 529-539

13. Atfi A, Buisine M, Mazars A and Gespach C (1997) Induction of apoptosis by DPC4, a transcriptional factor regulated by transforming growth factor-beta through stress-activated protein kinase/c-Jun N-terminal kinase (SAPK/JNK) signaling pathway. J. Biol. Chem. 272: 24731-24734

14. Chin YE, Kitagawa M, Kuida K, Flavell RA and Fu XY (1997) Activation of the STAT signaling pathway can cause expression of Caspase 1 and apoptosis. Mol. Cell. Biol. 17: 5328-5337

15. Moyer JD, Barbacci EG, Iwata KK, Arnold L, Boman B, Cunningham A, DiOrio C Doty J, Morin MJ, Moyer MP, Neveu M, Pollack VA, Pustilnik LR, Reynolds MM, Sloan D, Theleman A and Miller P (1997) Induction of apoptosis and cell cycle arrest by CP-358,774, an inhibitor of epidermal growth factor receptor tyrosine kinase. Cancer Res. 57: 4838-4848

16. Qin S, Minami Y, Hibi M, Kurosaki Tand YamamuraH (1997) Syk-dependent and -independent signaling cascades in B cells elicited by osmotic and oxidative stress. J. Biol. Chem. 272: 2098-2103

17. Imbert V, Peyron JF, Farahi Far D, Mari B, Auberger P and Rossi B (1994) Induction of tyrosine phosphorylation and $\mathrm{T}$-cell activation by vanadate peroxide, an inhibitor of protein tyrosine phosphatases. Biochem. J. 297: 163-173

18. Ullrich A and Schlessinger J (1990) Signal transduction by receptors with tyrosine kinase activity. Cell 61: 203-212

19. Zhao Z, Tan Z, Diltz CD, You M and Fischer EH (1996) Activation of mitogenactivated protein (MAP) kinase pathway by pervanadate, a potent inhibitor of tyrosine phosphatases. J. Biol. Chem. 271: 22251-22255

20. Huyer G, Liu S, Kelly J, Moffat J, Payette P, Kennedy B, Tsaprailis G, Gresser MJ and Ramachandran C (1997) Mechanism of inhibition of protein-tyrosine phosphatases by vanadate and pervanadate. J. Biol. Chem. 272: 843-851

21. Secrist JP, Burns LA, Karnitz L, Koretzky GA and Abraham RT (1993) Stimulatory effect of the tyrosine phosphatase inhibitor, pervanadate, on T-cell activation events. J. Biol. Chem. 268: 5886-5893

22. Wienands J, Larbolette $O$ and Reth M (1996) Evidence for a preformed transducer complex organized by the B cell antigen receptor. Proc. Natl. Acad. Sci. USA 93: 7865-7870
23. Imbert $\mathrm{V}$, Rupec RA, Livolsi A, Pahl HL, Traenckner EB, Mueller-Dieckmann C, Farahifar D, Rossi B, Auberger P, Baeuerle PA and Peyron JF (1996) Tyrosine phosphorylation of $\mid \kappa B-\alpha$ activates NF- $\kappa$ B without proteolytic degradation of $\mathrm{I}_{\kappa} \mathrm{B}$ a. Cell 86: 787-798

24. Garcia-Calvo M, Peterson EP, Leiting B, Ruel R, Nicholson DW and Thornberry NA (1998) Inhibition of human caspases by peptide-based and macromolecular inhibitors. J. Biol. Chem. 273: 32608-32613

25. Peter ME, Dhein J, Ehret A, Hellbardt S, Walczak H, Moldenhauer G and Krammer PH (1995) APO-1 (CD95)-dependent and -independent antigen receptor-induced apoptosis in human T and B cell lines. Int. Immunol. 7: 18731877

26. Chinnaiyan AM, O'Rourke K, Tewari M and Dixit VM (1995) FADD, a novel death domain-containing protein, interacts with the death domain of Fas and initiates apoptosis. Cell 81: 505-512

27. Juo P, Kuo CJ, Yuan J and Blenis J (1998) Essential requirement for caspase-8/ FLICE in the initiation of the Fas-induced apoptotic cascade. Curr. Biol. 8: 1001 1008

28. Zamzami N, BrennerC, Marzo I, Susin SA and Kroemer G (1998) Subcellular and submitochondrial mode of action of Bcl-2-like oncoproteins. Oncogene 16: 2265-2282

29. Green Dand Kroemer G (1998) The central executioners of apoptosis: Caspases or mitochondria? Trends Cell Biol. 8: 267-271

30. Hurley TR, Hyman R and Sefton BM (1993) Differential effects of expression of the CD45 tyrosine protein phosphatase on the tyrosine phosphorylation of the Ick, fyn, and c-src tyrosine protein kinases. Mol. Cell. Biol. 13: 1651-1656

31. Holgado Madruga M, Moscatello DK, Emlet DR, Dieterich Rand Wong AJ (1997) Grb2-associated binder-1 mediates phosphatidylinositol3-kinase activation and the promotion of cell survival by nerve growth factor. Proc. Natl. Acad. Sci. USA 94: $12419-12424$

32. Eischen CM, Dick CJ and Leibson PJ (1994) Tyrosine kinase activation provides an early and requisite signal for Fas-induced apoptosis. J. Immunol. 153: 1947 1954

33. Simon HU, Yousefi S, Dibbert B, Hebestreit H, Weber M, Branch DR, Blaser K, Levi Schaffer F and Anderson GP (1998) Role for tyrosine phosphorylation and Lyn tyrosine kinase in fas receptor-mediated apoptosis in eosinophils. Blood 92: 547-557

34. Cardone MH, Salvesen GS, Widmann C, Johnson G and Frisch SM (1997) The regulation of anoikis: MEKK-1 activation requires cleavage by Caspases. Cell 90: $315-323$

35. Deak JC, Cross JV, Lewis M, Qian Y, Parrott LA, Distelhorst CW and Templeton DJ (1998) Fas-induced proteolytic activation and intracellular redistribution of the stress-signaling kinase MEKK1. Proc. Natl. Acad. Sci. USA 95: 5595-5600

36. Widmann C, Gerwins P, Johnson NL, Jarpe MB and Johnson GL (1998) MEK kinase 1 , a substrate for DEVD-directed caspases, is involved in genotoxininduced apoptosis. Mol. Cell. Biol. 18: 2416-2429

37. Saras J, Engstrom U, Gonez LJ and Heldin CH (1997) Characterization of the interactions between PDZ domains of the protein-tyrosine phosphatase PTPL1 and the carboxyl-terminal tail of Fas. J. Biol. Chem. 272: 20979-20981

38. Sato T, Irie S, Kitada S and Reed JC (1995) FAP-1: a protein tyrosine phosphatase that associates with Fas. Science 268: $411-415$

39. Cuppen E, Nagata S, Wieringa B and Hendriks W (1997) No evidence for involvement of mouse protein-tyrosine phosphatase-BAS-like Fas-associated phosphatase-1 in Fas-mediated apoptosis. J. Biol. Chem. 272: 30215-30220

40. Runden E, Seglen PO, Haug FM, Ottersen OP, Wieloch T, Shamloo Mand Laake $\mathrm{JH}$ (1998) Regional selective neuronal degeneration after protein phosphatase inhibition in hippocampal slice cultures: evidence for a MAP kinase-dependent mechanism. J. Neurosci. 18: 7296-7305

41. Guo YL, Kang B and Williamson JR (1998) Inhibition of the expression of mitogen-activated protein phosphatase-1 potentiates apoptosis induced by tumor necrosis factor- $\alpha$ in rat mesangial cells. J. Biol. Chem. 273: 10362-10366

42. Darnay BG and Aggarwal BB (1997) Inhibition of protein tyrosine phosphatases causes phosphorylation of tyrosine 331 in the p60 TNF receptor and inactivates the receptor-associated kinase. FEBS Lett. 410: 361-367

43. Nicoletti I, Migliorati G, Pagliacci MC, Grignani F and Riccardi C (1991) A rapid and simple method for measuring thymocyte apoptosis by propidium iodide staining and flow cytometry. J. Immunol. Method. 139: 271-279 
44. Dumont A, Hehner SP, Hofmann TG, Ueffing M, Dröge W and Schmitz ML (1999) Hydrogen peroxide-induced apoptosis is CD95-independent, requires the release of reactive oxygen species and the activation of NF- $\kappa$ B. Oncogene 18 : $747-757$
45. Scaffidi C, Medema JP, Krammer PH and Peter ME (1997) FLICE is predominantly expressed as two functionally active isoforms, Caspase-8/a and Caspase-8/b. J. Biol. Chem. 272: 26953-26958 